\title{
What affects the outcome of severe preeclampsia?
}

\author{
VESNA ELVEĐI-GAŠPAROVIĆ ${ }^{1}$, PETRANA BELJAN ${ }^{1}$ SNJEŽANA GVERIĆ AHMETAŠEVIĆ ${ }^{1}$, SNJEŽANA SCHUSTER ${ }^{2,}$ SNJEŽANA SKRABLIN ${ }^{l}$ \\ ${ }^{1}$ Department of $O B / G Y N$, School of Medicine, University of Zagreb, Zagreb, Croatia \\ ${ }^{2}$ University of Applied Health Sciences, Zagreb, Croatia
}

Corresponding author:

Petrana Beljan

Department of OB/GYN, School of Medicine, University of Zagreb

Petrova 3, 10000 Zagreb,

Phone: 01/4604-728

E-mail:p.beljan@yahoo.com

\section{ABSTRACT}

Preeclampsia is a severe multi-system pregnancy related disorder associated with multiple maternal and fetal adverse outcomes, including fetal and maternal mortality. The aim of this study is to investigate the clinical difference between early- and late-onset preeclampsia and their impact to perinatal outcome, and to detect possible antenatal parameters that can predict adverse fetal and maternal outcomes. The research team conducted a retrospective cohort study of 308 singleton pregnancies complicated with severe preeclampsia over an 8-year period in our tertiary level centre. Clinical differences and perinatal outcomes between early- $(<34$ weeks, $\mathrm{n}=147$ ) and late-onset ( $\geq 34$ weeks, $\mathrm{n}=161$ ) preeclampsia were analyzed. Possible antenatal risk factors that can influence adverse perinatal outcomes in severe preeclampsia were also evaluated. Clinical symptoms and perinatal outcomes were significantly unfavourable in early-onset preeclampsia. Adverse perinatal outcomes in the early-onset group were complicated with $10(6.08 \%)$ intrauterine fetal deaths and $4(2.37 \%)$ neonatal deaths. Primiparity seems to be the significant antenatal risk factor for appearance of early-onset of the disease $(\mathrm{p}<0.001$, OR $2.39,95 \%$ CI 1.48-3.86) and for the first minute Apgar score $<7$ ( $p=0.036$, OR $1.68,95 \%$ CI 1.04 2.74). Patients with severe preeclampsia are high- risk obstetric patients because of the unpredictability, varying clinical presentation and potential adverse outcomes of the disease. Pregnant women with an early appearance of the disease had severe clinical presentation and more often an unfavourable perinatal outcome.

Key words: early-onset preeclampsia, perinatal outcome, HELLP

\section{INTRODUCTION}

Preeclampsia (PE) is a severe multi-system pregnancy related disorder that causes complications in 3-7\% of all pregnancies. $(1,2) \mathrm{PE}$ is associated with multiple maternal and fetal adverse effects. It is also a major cause of fetal and maternal mortality worldwide. (3) The main clinical features of this disorder are hypertension (elevated blood pressure over $140 \mathrm{mmHg}$ systolic and $90 \mathrm{mmHg}$ diastolic) and proteinuria (presence of protein in the urine more than $300 \mathrm{mg}$ per day) in previously normotensive women after 20 weeks gestation. (4) Other signs and symptoms include edema and headache (in severe cases, the condition is associated with seizures called eclampsia), liver and kidney damage, clotting abnormalities, adult respiratory distress syndrome and fetal growth restriction. (5) It can lead to pulmonary edema and kidney or liver failure. Neonatal complications of PE include preterm delivery, fetal growth restriction, hypoxia-related neurologic injury, perinatal death and long-term cardiovascular morbidity associated with low birth weight. (6) The etiology of PE has not as of yet been clearly defined. It is believed that the placenta plays a key role in the pathophysiology of preeclampsia (because the symptoms and complications of preeclampsia disappear after delivery of the placenta), as well as endothelial dysfunction and incomplete or absent trophoblast invasion to the uterine spiral arteries, which is related to reduced uteroplacental blood flow and placental ischemia. $(7,9)$ Factors that increase the risk for preeclampsia development in a woman include prior history of preeclampsia, chronic hypertension, nulliparous, chronic kidney disease, pregestational diabetes, multiple gestations, obesity and age $>40$ years old. (10) The issue is that millions of women worldwide have these risk factors but do not develop PE. Over the last 50 years, much progress has been made in improving treatment of preeclampsia with respect to blood pressure control and prevention of eclamptic seizures. However, the etiology and pathogenesis of this condition remain inaccessible resulting in failure to develop specific preventive and treatment strategies. Currently there is no definitive treatment or effective prophylaxis for preeclampsia in clinical use. Delivery and removal of the placenta is the only safe treatment, often premature. Close surveillance of mother and fetus is necessary for the timing of delivery in order to reduce morbidity and mortality rates. The aim of this study is to investigate the clinical ifference between early- and late-onset preeclampsia and the impact of their outcome on mother and newborn, as well as to detect possible antenatal parameters that can predict adverse perinatal outcomes.

\section{MATERIALS AND METHODS}

This retrospective cohort study was conducted at the Department of Obstetrics and Gynecology at the University of Zagreb School of Medicine. This research has the approval of the Ethical Committee as a part of our ten-year project "Premature Birth Risk Factors". Data for the study were collected from all patients $>24$ weeks of gestation, over a period of eight years (January 2007 till June 2014), with a diagnosis of severe preeclampsia in their medical record. A total number of 308 singleton pregnancies complicated with severe preeclampsia were enrolled in this study. The classification of preeclampsia was based on the American College of Obstetricians and Gynecologists guidelines. (11) 
Patients who suffered from chronic hypertension or gestational diabetes mellitus syndrome were excluded from the study. Gestational age was calculated from the first day of the last menstrual period. Patients with severe preeclampsia were divided into two groups according to the gestational age at the onset of preeclampsia; the "early-onset group" (preeclampsia onset before 34 weeks of gestation, $N=147$ ) and the "late-onset group" (preeclampsia onset at 34 or more weeks of gestation, $\mathrm{N}=161$ ). Clinical and laboratory characteristics and perinatal outcomes between early- and late-onset of the disease were evaluated. Severe preeclampsia is defined as gestational hypertension (systolic BP $\geq 160 \mathrm{mmHg}$ and/or diastolic $\mathrm{BP} \geq 100 \mathrm{mmHg}$ on at least 2 occasions $4 \mathrm{~h}$ apart after 20 weeks gestation, but before the onset of labour with proteinuria ( $\geq 500 \mathrm{mg} / 24 \mathrm{~h}$ or spot urine protein or urine dipstick protein $>=++$ ). Data were collected from maternal and neonatal records. The following perinatal outcomes were analyzed and compared: birth weight, fetal/neonatal death,1st minute and 5th minute Apgar scores $<7$, intrauterine growth restriction (fetal weight below the 10th percentile for gestational age), neonatal brain damage (intracranial haemorrhage or periventricular leukomalacia) and respiratory distress syndrome (RDS). The following maternal clinical and laboratory characteristics were evaluated: maternal age, gestational age, parity, body mass index (BMI, $\mathrm{kg} / \mathrm{m} 2$ ) and the highest values of the systolic and diastolic blood pressure during the therapy. Laboratory parameters included: maternal complete blood count (including the highest level of thrombocytes and aminotransferases) and proteins collected in $24 \mathrm{~h}$ urine. Pregnancy complications such as placental abruption or severe postpartum bleeding were evaluated. Statistical analysis was performed using SPSS version 21.0 (SPSS Inc., Chicago, IL, USA). Descriptive statistics were computed for continuous and categorical variables. The statistics computed included mean, standard deviation and number of available observations of continuous variables which are presented as mean \pm SD. Frequencies are presented for the categorical variables between the groups. We used the two sample t-test for testing the differences of continuous variables. Categorical variables were analysed using the $\chi 2$-test or the Fisher's exact test. We used the logistic regression model to assess the independence of specific perinatal outcome param- eters from prognostic factors. The level of significance was $\mathrm{p}<0.05$.

\section{RESULTS}

In our hospital there were 308 patients with severe preeclampsia during an 8 year period. The prevalence of severe preeclampsia was $0.96 \% .147$ patients ( $47.7 \%)$ had earlyonset preeclampsia $(<34$ weeks of gestation), and 161 (52.3\%) had late-onset of the disease ( $\geq 34$ weeks of gestation). The mean gestational age at delivery was significantly lower in the early-onset group $(32 \pm 2.65$ vs. $38.88 \pm 1.46$ weeks, $p<0.001)$. About $48 \%$ of patients from the early-onset group and $64 \%$ from the late-onset group were primiparas. Patients from the early-onset group had significantly higher mean blood pressure $(173.78 / 110.65 \mathrm{mmHg}$ vs. 163.72 /104.25 mmHg, $\mathrm{p}<0.001)$ and significantly higher aminotransferase levels (AST $44.33 \pm 48.32$, ALT $38.52 \pm 37.52$ vs. AST $21.21 \pm 20.14$, ALT 18.67 $\pm 16.49, \mathrm{p}<0.001$ ). Patients from the late-onset group had significantly more previous pregnancies in their medical history ( $46.58 \%$ vs. $21.77 \%$, $\mathrm{p}<0.001)$ with no differences in abortion rates between the groups. Mothers from the late-onset group had a higher mean age $(29.79 \pm 5.49$ vs. $29.24 \pm 5.89, \mathrm{p}=0.412)$ and BMI index score $(26.23 \pm 5.92$ vs. $24.66 \pm 4.51, \mathrm{p}=0.019)$. We found no significant differences in thrombocyte count (188.92 \pm 73.44 vs. $194.90 \pm 84.84, \mathrm{p}=0.532)$ and no significant differences in total urinary protein excretion between the groups $(3378.03 \pm 2700.72$ vs. $1822.45 \pm 1791.82$, $\mathrm{p}=0.130)($ table 1$)$.

Significant difference in adverse perinatal outcomes in the early-onset group were complicated with $10(6.08 \%)$ intrauterine fetal deaths and $4(2.37 \%)$ neonatal deaths. Five children from the same group had intracranial haemorrhage and two of them died. 15\% of newborns had neonatal sepsis and were admitted to the Neonatal Intensive Care Unit (NICU). Birth weight of newborns from the early-onset group were significantly lower $(1485.75 \pm 502.15$ vs. $3229.43 \pm 592.95, \mathrm{p}<0.001)$. Intrauterine growth restriction (IUGR) was evident in 30 newborns from the early-onset group $(20.4 \%)$ vs. 8 (11.3\%) from late-onset group $(\mathrm{p}=0.027)$. Respiratory distress syndrome (RDS) occured in $32(21.8 \%)$ newborns from the early-onset preeclampsia group and none occurred in the lateonset group. Intracranial haemorrhage
(ICH) was found in 5 (3.4\%) newborns and periventricular leukomalacia (PVL) in $13(8.8 \%)$ newborns from the early-onset group $(p<0.001)$. Significantly higher rates of neonatal asphyxia in the early-onset group included lower Apgar scores in the 1st $(5.97 \pm 2.97$ vs. $9.23 \pm 1.90, \mathrm{p}<0.001)$ and the 5 th minute $(7.45 \pm 2.69$ vs. $9.67 \pm 0.77$, $\mathrm{p}<0.001)$ and neonatal umbilical $\mathrm{pH}<7.0$ (34 vs. 9, p<0.001) (table 2). Analyzing possible antenatal risk factors with an influence to adverse perinatal outcomes in severe preeclampsia, primiparity seems to have the most influence for the appearance of early-onset of the disease $(\mathrm{p}<0.001$, OR 2.39, 95\% CI 1.48-3.86) and 1st minute Apgar score $<7 \quad(\mathrm{p}=0.036$, OR 1.68 , 95\% CI 1.04-2.74). Systolic blood pressure $>160 \mathrm{mmHg}(\mathrm{p}<0.001$, OR 1.10, 95\% CI 1.06-1.12) and diastolic blood pressure $>100 \mathrm{mmHg}(\mathrm{p}<0.001$, OR $1.10,95 \%$ CI $1.07-1.17$ ) are possible risk factors for the appearance of early-onset of the disease and eclamptic seizure $(\mathrm{p}=0.002$, OR 1.10 , 95\% CI 1.03-1.16, $\mathrm{P}=0.003, \mathrm{OR}=1.16$, 95\%CI 1.05-1.27). Maternal age, BMI, liver enzyme levels, $24 \mathrm{~h}$ proteinuria and thrombocytopenia have no influence in unfavourable perinatal outcomes (table 3).

\section{DISCUSSION}

Preeclampsia is a pregnancy associated disease occurring mainly after the 20th week of gestation. The organs being affected by preeclampsia include the hepatic, renal, vascular, cerebral, and coagulation systems. The majority of adverse pregnancy outcomes occurred in women who developed severe preeclampsia prior to 34 weeks of gestation and in those women with previous pre-existing vascular disease. (11) The incidences of severe preeclampsia prior to the 34th week of gestation is $0.3 \%$, and in many countries preeclampsia is still the most frequent cause of maternal perinatal mortality. (12) Preterm delivery is not always in the best interest of the fetus, and a decision to delay delivery can be considered under certain circumstances. Expectant management in severe preeclampsia is a reasonable approach for some patients, but it must be emphasized that this approach is not associated with any direct maternal benefits. The mother is undertaking a significant risk to her own health. The ability to predict preeclampsia is currently of limited benefit because neither the development of the disease, 
nor its progression from a mild to a severe disease, can be prevented in most patients so detecting possible antenatal parameter that can predict adverse perinatal outcomes was of utmost importance for us. During the investigation of clinical differences between early- and late-onset preeclampsia, our results endorsed the finding that during the early form of the disease, terminated preterm has a significantly adverse perinatal outcome. Our study found that many significant differences were apparent between early-onset preeclampsia and late-onset preeclampsia. Groups were significantly different in maternal characteristics according to maternal parity, grade of hypertension, liver enzyme levels and maternal BMI. It is unclear why the primigravid state is such an important predisposing factor, but as many authors verified, $(13,14)$ we clearly affirmed that the early onset of the disease was more frequent in first pregnancy $(\mathrm{p}<0.001)$. Hypertension is generally the earliest clinical finding of preeclampsia and is the most common clinical clue to the presence of the disease. We found that the grade of hypertension was higher in the early-onset group $(\mathrm{p}<0.001)$ and that liver enzyme levels were also higher in the early onset of the disease $(\mathrm{p}<0.001)$. The most impressive differences referred to an adverse perinatal outcome in the early-onset group with a higher rate of intrauterine death $(6.08 \%$ vs. $0 ; \mathrm{p}<0.001)$, lower Apgar scores in the 1st (5.97 vs. $9.23 ; \mathrm{p}<0.001)$ and 5 th minutes (7.45 vs. 9.67; $\mathrm{p}<0.001)$ and as in Reiss et al. paper (15), in fetal acidosis (23.23\% vs. $5.95 \% ; \mathrm{p}<0.001)$. The study of Bucbinder et al. showed the differences in the incidence of intrauterine death due to the severity of preeclampsia, where the severe forms had a higher frequency of intrauterine death. (16) Just as our results showed, Lisonkova found that early-onset preeclampsia was significantly associated with high risk of fetal death (AOR, 5.8; 95\% confidence interval CI, 4.0 - 8.3), but late-onset preeclampsia was not (AOR, 1.3; 95\% CI, 0.8 2.0) (17). The AOR for perinatal death was significant for both early-onset (16.4; 95\% CI, 14.5 - 18.6) and late-onset (2.0; 95\% CI, 1.8 - 2.3) preeclampsia. In almost the same number of patients as in our study, Sibai detected 28 intrauterine and 17 neonatal deaths (18), which represents about $14 \%$ and is considerably higher than in our results. In the same study there were 17 cases of placental abruptions (5.6\%). In our study however, we found 11 cases of pla- cental abruptions in the early-onset group $(7.5 \%)$, and 5 cases in the late-onset group (3.1\%, $\mathrm{p}=0.084)$. Better perinatal outcomes in this segment may be due to the fact that most of our patients were transferred to our hospital, which is a tertiary level medical centre, as "transport in utero" from regional hospitals. The procedures and measures provided in the tertiary level centre led to a substantial reduction of intrauterine fetal deaths in the early-onset preeclampsia group and no intrauterine fetal deaths in the late-onset preeclampsia group. Preeclampsia is inconsistently associated with intrauterine growth retardation. The determinants that explain the variability of this association are unknown. According to our results, the appearance of IUGR and Sy. HELLP appeared more frequent in the early-onset group (table 2). Geyl et al. also found that preeclampsia that appeared earlier was more severe in the group with IUGR and that fetal issues were more unfavourable when IUGR was associated with preeclampsia (19), whereas Srinivas et al. reported IUGR in $27 \%$ (20). In comparison to Stubert et al. (21), our study found differences in many maternal characteristics and known risk factors for preeclampsia, such as grade of hypertension $(\mathrm{p}<0.001)$, parity $(\mathrm{p}<0.001)$, liver enzyme levels $(\mathrm{p}<0.001)$, renal function $(\mathrm{p}=0.004)$ and BMI $(\mathrm{p}=0.019)$. Just as in our results, an association with BMI and the appearance of preeclampsia was emphasized in the results of Boghossian et al. (22), while Schummers et al. strongly advocates that with pre-pregnancy weight loss counselling and defining achievable weight loss, patients may reduce their risk of poor perinatal outcomes. (23) An estimation of $24 \mathrm{~h}$ urine proteins, a commonly performed investigation to assess proteinuria in pre-eclamptic women, and renal dysfunction leading to proteinuria, has commonly been used to predict adverse pregnancy outcomes. Proteinuria in preeclampsia occurs due to altered glomerular permeability and changes in tubular reabsorption of filtered proteins. In the present study, proteinuria did not differ between the groups, but in contrast to Nischintha et al. (24),we found a positive correlation with severe proteinuria and adverse perinatal outcomes regarding the lower 1st minute Apgar score $(\mathrm{p}=0.02)$ and abruption of the placenta $(\mathrm{p}=0.032)$.

As we expected, RDS, ICH and PVL were more frequent in the early-onset group as a direct consequence of preterm delivery.
Some studies suggest that preeclampsia decreases risk of cerebral palsy. $(25,26)$ The association between maternal preeclampsia and unfavourable neonatal neurodevelopment outcomes has been recently studied, concluding that infants exposed to preeclampsia have higher scores on developmental testing at 18 months corrected age. (27)

\section{CONCLUSION}

Patients with severe preeclampsia are high- risk obstetric patients because of unpredictability, varying clinical presentation and potential adverse outcomes of the disease. Pregnant women with early appearance of the disease had severe clinical presentation and more often unfavourable perinatal outcomes. Beyond a preeclampsia diagnosis, there is a high medical need for more reliable predictive markers for preeclampsia in order to improve maternal and fetal outcomes. 
Table 1. Maternal characteristics

\begin{tabular}{llll}
\hline & $\begin{array}{l}\text { Early onset group } \\
\mathbf{N}=\mathbf{1 4 7}\end{array}$ & $\begin{array}{l}\text { Late onset group } \\
\mathbf{N}=\mathbf{1 6 1}\end{array}$ & P-value \\
\hline Age (years) & $29.24 \pm 5.29$ & $29.79 \pm 5.79$ & 0.412 \\
\hline Primipara & $115(78.23 \%)$ & $86(53.42 \%)$ & $<0.001$ \\
\hline Multipara & $32(21.77 \%)$ & $75(46.58 \%)$ & $<0.001$ \\
\hline Gestational age at birth (weeks) & $32 \pm 2.65$ & $38.88 \pm 1.46$ & $<0.001$ \\
\hline $\begin{array}{l}\text { Highest value of systolic blood pres- } 173.78 \pm 15.73 \\
\text { sure (mm Hg) }\end{array}$ & $163.72 \pm 7.24$ & $<0.001$ \\
\hline $\begin{array}{l}\text { Highest value of diastolic blood } \\
\text { pressure }(\mathrm{mmHg})\end{array}$ & $110.65 \pm 10.17$ & $104.25 \pm 6.38$ & $<0.001$ \\
\hline BMI $(\mathrm{kg} / \mathrm{m} 2)$ & $26.23 \pm 5.92$ & $24.66 \pm 4.51$ & 0.019 \\
\hline AST $(\mathrm{U} / \mathrm{L})$ & $44.33 \pm 48.32$ & $21.21 \pm 20.14$ & $<0.001$ \\
\hline ALT $(\mathrm{U} / \mathrm{L})$ & $38.52 \pm 37.52$ & $18.67 \pm 16.49$ & $<0.001$ \\
\hline Thrombocytes $(\mathrm{x} 109 / \mathrm{L})$ & $188.92 \pm 73.44$ & $194.90 \pm 84.84$ & 0.532 \\
\hline Potassium $(\mathrm{mmol} / \mathrm{L})$ & $4.4 \pm 0.39$ & $4.27 \pm 0.39$ & 0.013 \\
\hline Creatinine $(\mu \mathrm{mol}(\mathrm{L})$ & $76.9 \pm 23.17$ & $72.40 \pm 13.09$ & 0.004 \\
\hline Proteins in $24 \mathrm{~h}$ urine $(\mathrm{mg} / \mathrm{L})$ & $3378.03 \pm 2700.72$ & $1822.45 \pm 1791.82$ & 0.130 \\
\hline
\end{tabular}

Data are presented as mean $\pm \mathrm{SD}$, or $\mathrm{N}$

BMI- body mass index $(, \mathrm{kg} / \mathrm{m} 2)$

ALT-alanine aminotransferase

AST-aspartate aminotransferase

Table 2. Perinatal outcome

\begin{tabular}{llll}
\hline & $\begin{array}{l}\text { Early onset } \\
\mathbf{N}=\mathbf{1 4 7}\end{array}$ & $\begin{array}{l}\text { Late onset } \\
\mathbf{N}=\mathbf{1 6 1}\end{array}$ & P-value \\
\hline Birth weight $(\mathrm{g})$ & $1485.75 \pm 502.15$ & $3229.43 \pm 592.95$ & $<0.001$ \\
\hline Intrauterine death & $10(6.08 \%)$ & 0 & $<0.001$ \\
\hline Neonatal death & $4(2.37 \%)$ & 0 & 0.035 \\
\hline 1st minute Apgar score & $5.97 \pm 2.97$ & $9.23 \pm 1.90$ & $<0.001$ \\
\hline 5th minute Apgar score & $7.45 \pm 2.69$ & $9.67 \pm 0.77$ & $<0.001$ \\
\hline Umbilical ph<7.0 & $34(23.23 \%)$ & $9(5.59 \%)$ & $<0.001$ \\
\hline RDS & $32(21.8 \%)$ & 0 & $<0.001$ \\
\hline ICH & $5(3.4 \%)$ & 0 & 0.018 \\
\hline PVL & $13(8.8 \%)$ & 0 & $<0.001$ \\
\hline IUGR & $30(20.4 \%)$ & $8(11.3 \%)$ & 0.027 \\
\hline Placental abruption & $11(7.55 \%)$ & $5(3.1 \%)$ & 0.084 \\
\hline Eclampsia & $2(1.36 \%)$ & $1(0.63 \%)$ & 0.509 \\
\hline Sy. HELLP & $11(7.48 \%)$ & $2(1.24 \%)$ & 0.032 \\
\hline
\end{tabular}

HELLP-hemolysis, elevated liver enzymes, low platelet count

ICH- intracranial hemorrhage

IUGR- intrauterine growth restriction

PVL-periventricularleukomalacia

RDS- respiratory distress syndrome

Table 3. Possible predicting factors for adverse perinatal outcome in severe preeclampsia 


\begin{tabular}{|c|c|c|c|c|}
\hline Perinatal outcome & Predicting factor & P-value & OR & $95 \% \mathrm{CI}$ \\
\hline \multirow[t]{9}{*}{ Intrauterine fetal death } & Primipara & 0.950 & 1.04 & $0.29-3.76$ \\
\hline & Maternal ag & 0.414 & 0.95 & $0.85-1.07$ \\
\hline & BMI & 0.270 & 1.08 & $0.94-1.23$ \\
\hline & Thrombocytes & 0.010 & 0.99 & $0.98-0.99$ \\
\hline & AST & 0.790 & 1.01 & $0.99-1.02$ \\
\hline & ALT & 0.709 & 0.99 & $0.91-1.02$ \\
\hline & Proteins (24h urine) & 0.239 & 1.00 & $1.00-1.00$ \\
\hline & Systolic blood press. & 0.426 & 1.02 & $0.98-1.06$ \\
\hline & Diastolic blood press. & 0.285 & 1.03 & $0.97-1.10$ \\
\hline \multirow[t]{9}{*}{ Neonatal death } & Primipara & 0.781 & 1.39 & $0.13-15.52$ \\
\hline & Maternal age & 0.781 & 1.01 & $0.82-1.24$ \\
\hline & BMI & 0.046 & 1.25 & $1.04-1.55$ \\
\hline & Thrombocytes & 0.620 & 1.01 & $0.99-1.02$ \\
\hline & AST & 0.528 & 0.97 & $0.87-1.08$ \\
\hline & ALT & 0.603 & 0.98 & $0.91-1.06$ \\
\hline & Proteins (24h urine) & 0.818 & 1.00 & $1.00-1.00$ \\
\hline & Systolic blood press. & 0.081 & 1.05 & $0.99-1.11$ \\
\hline & Diastolic blood pres. & 0.273 & 1.05 & $0.96-1.16$ \\
\hline \multirow[t]{9}{*}{ Early onset of preeclampsia } & Primipara & $<0.001$ & 2.39 & $1.48-3.86$ \\
\hline & Maternal age & 0.290 & 0.98 & $0.94-1.02$ \\
\hline & BMI & 0.937 & 0.10 & $0.95-1.06$ \\
\hline & Thrombocytes & 0.004 & 0.99 & $0.99-1.00$ \\
\hline & AST & $<0.001$ & 1.03 & $1.02-1.05$ \\
\hline & ALT & $<0.001$ & 1.03 & $1.02-1.05$ \\
\hline & Proteins (24h urine) & 0.581 & 1.00 & $1.00-1.00$ \\
\hline & Systolic blood press. & $<0.001$ & 1.10 & $1.06-1.12$ \\
\hline & Diastolic blood pres. & $<0.001$ & 1.10 & $1.07-1.14$ \\
\hline \multirow[t]{9}{*}{ 1st minute Apgar score $<7$} & Primipara & 0.036 & 1.68 & $1.04-2.74$ \\
\hline & Maternal age & 0.684 & 0.99 & $0.96-1.03$ \\
\hline & BMI & 0.828 & 1.01 & $0.95-1.06$ \\
\hline & Thrombocytes & 0.043 & 0.97 & $0.99-1.00$ \\
\hline & AST & 0.008 & 1.01 & $1.00-1.02$ \\
\hline & ALT & 0.011 & 1.01 & $1.00-1.02$ \\
\hline & Proteins (24h urine) & 0.086 & 1.00 & $1.00-1.00$ \\
\hline & Systolic blood press. & 0.001 & 1.03 & $1.01-1.07$ \\
\hline & Diastolic blood press. & 0.001 & 1.05 & $1.02-1.07$ \\
\hline \multirow[t]{9}{*}{ Abruptio placentae } & Primipara & 0.599 & 0.77 & $0.29-2.05$ \\
\hline & Maternal age & 0.652 & 0.91 & $0.89-1.07$ \\
\hline & BMI & 0.714 & 1.02 & $0.91-1.14$ \\
\hline & Thrombocytes & 0.092 & 0.99 & $0.98-1.00$ \\
\hline & AST & 0.541 & 1.00 & $0.99-1.01$ \\
\hline & ALT & 0.436 & 1.00 & $0.99-1.02$ \\
\hline & Proteins (24h urine) & 0.848 & 1.00 & $1.00-1.00$ \\
\hline & Systolic blood press. & 0.608 & 1.01 & $0.98-1.04$ \\
\hline & Diastolic blood press. & 0.522 & 1.02 & $0.97-1.07$ \\
\hline
\end{tabular}




\begin{tabular}{lllll}
\hline Eclamptic seizure & Primipara & 0.995 & 0.00 & 0.00 \\
\cline { 2 - 4 } Maternal age & 0.547 & 1.07 & $0.87-1.31$ \\
\hline BMI & 0.652 & 1.06 & $0.83-1.35$ \\
\hline Thrombocytes & 0.869 & 1.01 & $0.99-1.02$ \\
\hline AST & 0.760 & 1.01 & $0.99-1.03$ \\
\hline ALT & 0.401 & 1.01 & $0.98-1.00$ \\
\hline Proteins (24h urine) & 0.577 & 0.99 & $1.03-1.16$ \\
\hline Systolic blood press. & 0.002 & 1.10 & $1.05-1.27$ \\
\hline Diastolic blood press. & 0.003 & 0.479 & 1.16 & $0.39-1.54$ \\
\hline Primipara & 0.853 & 0.78 & $0.94-1.06$ \\
\hline Maternal age & 0.882 & 0.99 & 0.93 .1 .01 \\
\hline BMI & Thrombocytes & 0.647 & 1.01 & $0.99-1.00$ \\
\hline AST & 0.161 & 0.99 & $1.00-1.01$ \\
\hline ALT & 0.508 & 1.01 & $0.99-1.01$ \\
\hline Proteins (24h urine) & 0.972 & 1.01 & $1.00-1.00$ \\
\cline { 2 - 4 } & Systolic blood press. & 0.430 & 1.00 & $0.99-1.03$ \\
\hline Diastolic blood pres. & 0.094 & 1.01 & $0.99-1.06$ \\
\hline
\end{tabular}

Underline emphasis of $\mathrm{P}$-values represents statistical significance $(\mathrm{P}<0.05)$

BMI- body mass index $(\mathrm{kg} / \mathrm{m} 2)$

ALT-alanine aminotransferase

AST-aspartate aminotransferase

\section{REFERENCES}

1. Lindheimer MD, Roberts JM and Cunningham FG. Chesley's hypertensive disorders in pregnancy. 3rd ed.Amsterdam :ElsevierInc; 2009.

2. Surapaneni T, PatilBada V, and Kumar Nirmalan CP. Risk of recurrence of pre-eclampsia in the subsequent pregnancy. JCDR 2013;7:2889-2891.

3. World Health Organization. Make Every Mother and Child Count. World Health Report; 2005; World Health Organization, Geneva. Switzerland.

4. Brown MA, Lindheimer MD, De Swiet M, Van Assche A, Moutquin JM. The classification and diagnosis of the hypertensive disorders of pregnancy: statement from the international society for the study of hypertension in pregnancy (ISSHP). Hypertension in Pregnancy 2001;20(1):9-14.

5. Davison JM, Homuth V, Jeyabalan A. New aspects in the pathophysiology of Preeclampsia. J Am SocNephrol2004;15:2440-2448.

6. Sibai B, Dekker G, Kupferminc M. Pre-eclampsia. Lancet 2005;365:785-799.

7. Roberts JM, Escudero C. The placenta in preeclampsia.Pregnancy Hypertension. 2012;2(2):72-83.

8. Redman CW, Sargent IL. Latest advances in understanding preeclampsia. Science 2005;308(5728):1592-1594.

9. Davison JM, Homuth V, Jeyabalan A, et al. New aspects in the pathophysiology of preeclampsia. Journal of the American Society of Nephrology 2004;15(9):2440-2448.

10. Powe CE, Levine RJ, Karumanchi SA. Preeclampsia, a disease of the maternal endothelium: the role of antiangiogenic factors and implications for later cardiovascular disease. Circulation 2011;123:2856-2869.

11. Report of the National High Blood Pressure Education Program. Working group on High Blood Pressure in Pregnancy. Am J ObstetGynecol 2000;183:S1-22.

12. Publications Comitee, Society for Maternal-Fetal Medicine. Evaluation and management of severe preeclampsia before 34 weeks' gestation. Am J ObstetGynecol 2011;205:191.

13. Moon M, Odibo A. First-trimester screening for preeclampsia:impact of maternal parity on modeling and screening effectiveness. J Matern Fetal Neonatal Med 2014;11:1-6.

14. Duckitt K, Harrington D. Risk factors for preeclampsia at antenatal booking: systematic review of controlled studies. BMJ 2005;330:565-573.

15. Reis ZS, Lage EM, Teixeira PG, Guedes LR, Oliviera EC, Cabral AC. Early onsep preeclampsia: is it a better classification for maternal and perinatal outcome?. Rev Bras GinecolObstet2010;32:584-590.

16. Buchbinder A, Sibai BM, Caritis S. Adverse perinatal outcome are significantly higher in severe gestational hypertension than in mild preeclampsia. National Institute Of Child Health And Human Development Network Of Maternal-Fetal Medicine Units. Am J ObstetGynecol 2002;186:66-67.

17. Lisonkova S, Joseph KS. Incidence of preeclampsia: risk factors and outcomes associated with early- versus late-onset disease. Am J ObstetGynecol2013;209:544.e1-12.doi:10.1016/j.ajog.2013.08.019.

18. Sibai BM, Spinnato JA, Watson DL, Anderson GD. Pregnancy outcome in 303 cases with severe preeclampsia. Am J ObstetGynecol 1984;64(3):319322. 
19. Geyl C, Clouquer E, Lambert J, Subtil D, Debarge V, Deruelle P. Links between preeclampsia and intrauterine growth restriction. GynecolObstetFertil2014;42:229-233.

20. Srinivas SK, Edlow AG, Neff PM, Sammel MD, Andrela CM, Elovitz MA. Rethinking IUGR in preeclampsia: dependent or independent of maternal hypertension? J Perinatol2009;29(10):680-684. doi: 10.1038/jp.2009.83.

21. Stubert Ullman S, Dieterich M, Diedrich D, Reimer T. Clinical differences between early- and- late onset severe preeclampsia and analysis of predictors for perinatal outcome. J PerinatMed 2014;42:617-627.

22. Boghossian NS, Yeung E, Mendola P, Hinkle SN, Laughon SK, Zhang C, Albert PS. Risk factors differ between recurrent and incident preeclampsia: a hospital- based cohort study. Ann Epidemiol 2012;24:871-877.

23. Schummers L, Hutcheon JA, Bodnar LM, Lieberman E, Himes KP: Risk of adverse pregnancy outcomes by prepregnancu body mass index: a population -based study to inform prepregnancy weight loss counseling. ObstetGynecol 2015;125:133-143.

24. Nischintha P, PallaveeP, Seetesh G. Correlation between 24-urine protein, spot urine protein/creatinine ratio, and serum uric acid and their association with fetomaternal outcomes in preeclamptic women. J Nat SciBiolMed 2014;5:255-260.

25. Gray PH, O'Callaghan MJ, Mohay HA, Burns JR, King FK. Maternal hypertension and neurodevelopmental outcome in very preterm infants, Archives of Disease in Childhood: Fetal and Neonatal Edition1998;2(79): 88-93.

26. Silveira RC, Procianoy RS, Koch MS, Benjamin ACV, Schlindwein CF. Growth and neurodevelopment outcome of very low birth weight infants delivered by preeclamptic mothers. ActaPaediatrica, International Journal of Paediatrics 2007;12(96):1738-1742.

27. Saleem S, McClure EM, Goudar SS et al. Newborn Health Registry Study Investigators. A prospective study of maternal, fetal and neonatal deaths in low- and middle-income countries. Bull World Health Organ 2014;1;92(8):605-612. doi: 10.2471/BLT.13.127464. 